\title{
0 potencial formativo do Pibid pela perspectiva dos formadores de professores
}

\section{The PIBID formative potential from the perspective of teacher trainers}

\section{El potencial formativo del PIBID desde la perspectiva de los formadores de docentes}

http://dx.doi.org/10.21713/2358-2332.2016.v13.891

Elisa Prestes Massena, doutora em Educação pela Universidade Federal do Rio de Janeiro (UFRJ) e docente do Departamento de Ciências Exatas e Tecnológicas no curso de graduação em Química e no Programa de Pós-Graduação em Educação em Ciências da Universidade Estadual de Santa Cruz (Uesc), Ilhéus, BA, Brasil. E-mail: elisapmassena@gmail.com.

Maria Isabel da Cunha, doutora em Educação pela Universidade Estadual de Campinas (Unicamp) e professora titular do Programa de Pós-Graduação em Educação da Universidade do Vale do Rio dos Sinos (Unisinos), São Leopoldo,RS, Brasil. E-mail: cunhami@ uol.com.br.

\section{Resumo}

Este trabalho apresenta o potencial formativo a partir da experiência no Pibid, do ponto de vista de concepções e práticas, de formadores de professores atuantes no citado programa e em cursos de Licenciatura em Biologia, em Física e em Matemática, oriundos de três instituições de ensino superior do Sul do Brasil. Foram realizadas entrevistas semiestruturadas com nove docentes. Os dados, analisados à luz da Análise Textual Discursiva, apontam para o fato de que a experiência no interior do Pibid auxilia a repensar o currículo dos cursos de licenciatura nessas instituições, aproximando os docentes da realidade escolar e possibilitando o aprofundamento de temáticas que 
impactam a formação dos licenciandos. 0 estudo sinaliza também que ainda não é clara, para os formadores, a relação entre as contribuições do programa e seu desenvolvimento profissional docente.

Palavras-chave: Pibid. Formadores de Professores. Formação de Professores.

\section{Abstract}

This study presents the educational formative potential from the experience with PIBID, from practical and conceptual points of view of teacher trainers participating in the above mentioned program and in the teaching fields of Biology, Physics, and Mathematics of three higher education institutions in southern Brazil. Semi structured interviews were done with nine professors. The data, analysed through the light of Textual Discourse Analysis, point out that the experience in the PIBID helps to rethink the teaching degree curricula in these institutions, getting teachers closer to school reality and allowing the deepening of themes that impact the formation of teaching degree students. The study also indicates that for teacher trainers, the relationship between the Program 's contributions and their professional development as professors is still unclear.

Keywords: PIBID. Teacher Trainers. Teacher Training.

\section{Resumen}

Este artículo expone el potencial formativo de la experiencia en el PIBID desde el punto de vista de las concepciones y prácticas de los docentes formadores que trabajan en el citado programa y en los cursos de licenciatura en Biología, en Física y en Matemáticas, de tres instituciones de educación superior del Sur de Brasil. Se realizaron entrevistas semiestructuradas con nueve profesores. Los datos analizados a la luz del Análisis Textual Discursivo apuntan para el hecho de que la experiencia dentro del PIBID ayuda a repensar la 
estructura curricular de los cursos de licenciatura en estas instituciones, aproximando los docentes de la realidad escolar y permitiendo la profundización de temáticas que impactan en la formación de los estudiantes de licenciatura. El estudio también indica que aún no está claro, para los formadores, la relación entre las contribuciones del programa y su desarrollo profesional docente.

Palabras clave: PIBID. Formadores de Docentes. Formación de Profesores.

\section{INTRODUÇÃO}

O Programa Institucional de Bolsa de Iniciação à Docência (Pibid) foi instituído pela Coordenação de Aperfeiçoamento de Pessoal de Nível Superior (Capes), no Brasil, a partir de 2008, nas universidades públicas federais e, a partir de 2010, nas universidades estaduais, municipais e comunitárias (BRASIL, 2007; BRASIL, 2009). Desde então, tem sido um importante programa no que se configura como política pública de formação inicial e continuada de professores, principalmente por induzir "[...] mudanças formativas de docentes para a educação básica no âmbito das Instituições de Ensino Superior (IES)." (GATTI et al., 2014, p. 10).

Desde o início do Pibid, muitos têm sido os trabalhos publicados que trazem contribuições à formação inicial e continuada de professores. Os trabalhos publicados, em sua grande maioria, apontam melhorias nos processos de ensino e aprendizagem no contexto da escola onde são desenvolvidos os subprojetos (ARAÚJO, 2012; CARDOSO et al., 2012) e um maior empoderamento dos licenciandos, futuros professores, pela profissão (LEITE, 2012). Poucos são os trabalhos que apresentam reflexões de formadores de professores e, a partir destes, as contribuições para os cursos de formação de professores (AMBROSETTI, 2012; FELÍCIO, 2012; MASSENA, 2013).

O docente universitário, dentro dos cursos de licenciatura, assume um papel importante, pois dele depende a formação de futuros professores, e quando se pensa esse sujeito no interior de um programa de iniciação à docência existe a possibilidade de que mudanças oriundas dessa experiência impactem os cursos de formação de professores. 
Este estudo é parte integrante de uma pesquisa de pósdoutoramento desenvolvida pela primeira autora deste artigo. O objeto de investigação surgiu instigado pela experiência, vivenciada em mais de uma década, como formadora de professores para a educação básica e, mais recentemente, como coordenadora de subprojeto do Programa Institucional de Bolsa de Iniciação à Docência. O objetivo maior do estudo foi compreender o potencial formativo da experiência do Pibid, do ponto de vista das concepções e práticas pedagógicas, de formadores de professores de Biologia, de Física e de Matemática, coordenadores de subprojetos desse programa em três universidades (duas públicas e uma comunitária) do Sul do país. Para alcançar tal objetivo, algumas questões mais gerais nortearam o estudo: o formador universitário tem consciência de que também necessita investigar sua própria prática, quando forma futuros professores? Entende o processo de aprendizagem que vive nesse contexto? Como concebe o processo de seu próprio desenvolvimento profissional no subprojeto em que atua? As respostas a essas questões, ancoradas nas experiências vivenciadas no interior do Pibid, poderão contribuir para (re)pensar os cursos de licenciatura, o papel assumido pelos formadores na configuração de melhorias desses cursos e o desenvolvimento profissional desses docentes no interior dos cursos de formação.

\section{COMPREENDENDO O ESTUDO EMPREENDIDO}

O Pibid foi criado visando ao desenvolvimento da docência na escola básica e tem como principal objetivo a inserção do licenciando na escola e o acompanhamento de sua formação no ambiente escolar sob a supervisão de um professor dessa instituição ${ }^{1}$. A inserção na escola ocorre a partir do desenvolvimento de um subprojeto no estabelecimento

Considerando-se o ambiente escolar no contexto do PIBID existe a atuação de três sujeitos que assumem papéis específicos no interior do programa: o docente universitário denominado coordenador do subprojeto de determinada área; - professor da escola denominado de supervisor e o licenciando. de ensino pelo licenciando e o professor da escola sob a orientação do docente universitário. A perspectiva é a de que esse exercício favoreça a formação inicial do licenciando, pela possibilidade de inserção na cultura escolar e a compreensão dos saberes exercidos pelos professores da escola e pelos docentes da universidade. No entanto, o programa pode constituir uma experiência com potencial formativo para o exercício da docência do próprio professor universitário e dos professores da escola, 
pois existe a possibilidade de reflexão de novas aprendizagens desses sujeitos enquanto conduzem a formação dos futuros profissionais.

Por outro lado, a parceria universidade-escola tem auxiliado nas conquistas de espaços coletivos de interlocução do professorado, possibilitando um trabalho mais articulado entre pesquisadores da educação que atuam na universidade e professores da escola básica, validando a ação reflexiva na profissão docente (FELÍCIO; GOMES; ALLAIN, 2014; CARVALHO; RAZUCK, 2015).

Desde 2009, algumas portarias foram publicadas definindo o Pibid. De acordo com a Portaria nº 096, de 18 de julho de 2013, o programa assume a “ [...] finalidade de fomentar a iniciação à docência, contribuindo para o aperfeiçoamento da formação de docentes em nível superior e para a melhoria da qualidade da educação básica pública brasileira." (BRASIL, 2013, p. 2).

No seu art. $4^{\circ}$, item IV, a portaria define como um dos seus principais objetivos a inserção dos licenciandos no cotidiano de escolas da rede pública, o que deve proporcionar oportunidades de criação e participação em experiências metodológicas, tecnológicas e práticas docentes de caráter inovador e interdisciplinar. Como o Pibid representa uma possibilidade de que sejam elaborados subprojetos "livres" a serem desenvolvidos nas escolas, este aspecto põe em destaque a compreensão dos docentes universitários quanto às práticas curriculares e sua influência sobre a formação inicial de professores no contexto do programa. Isso possibilita que se pense na superação de problemas identificados nos processos de ensino e aprendizagem (tanto no exercício do futuro professor na escola, como no percurso na universidade), favorecendo uma reflexão sobre o currículo que sustenta as licenciaturas, bem como sobre a realidade das escolas da rede de educação básica.

Essas considerações revelam a importância de investigar o potencial formativo do programa na tentativa de compreender como os docentes universitários pensam/atuam no contexto da formação de seus cursos e como isso se reflete na docência universitária e no 
desenvolvimento profissional dos sujeitos envolvidos. Esse movimento encontra guarida no pensamento de Soares e Cunha (2010), que afirmam que

[...] o desenvolvimento profissional pressupõe tomar como ponto de partida e de chegada a prática profissional, objetivando o desenvolvimento de atitudes de reflexão e crítica sobre sua própria prática de ensino, quando priorizam as iniciativas dos próprios professores, em função da compreensão do caráter voluntário da formação, e quando investem na superação da perspectiva individualista da docência, apostando em ações colaborativas entre professores [...] (SOARES; CUNHA, 2010, p. 36).

O desenvolvimento profissional do docente universitário, em especial no que concerne aos aspectos didático-pedagógicos, tem sido objeto de crescente interesse de estudos e pesquisas, particularmente a partir das duas últimas décadas do século XX. A emergência da temática evidencia o reconhecimento da complexidade da docência universitária e a compreensão de que a identidade consolidada ao longo da trajetória secular dessa instituição, baseada no domínio dos conhecimentos específicos e na expertise profissional, não têm possibilitado que os professores respondam de forma proativa aos inúmeros desafios contemporâneos. Assim, o desenvolvimento profissional passa pela reflexão do professor sobre o próprio ambiente acadêmico, e isso, consequentemente, poderá gerar melhorias no processo de ensino e aprendizagem, nas compreensões do currículo e da sua relação com a formação de futuros professores.

A complexidade da docência universitária, nos últimos anos, vem provocando uma crise na identidade profissional dos docentes desse nível de ensino, expondo certa carência de formação específica para o exercício do magistério. Nesse sentido, Cunha, Soares e Ribeiro (2009, p. 7) ressaltam que a formação para a docência, no ensino superior, é centrada "em nível de pós-graduação, direcionada especialmente para o desenvolvimento de competências para a pesquisa", e que os "os saberes relacionados ao ensino, notadamente da graduação, têm sido silenciados e desvalorizados". Esse vácuo de saberes tem sido mais evidente diante dos desafios da democratização da universidade, que vem fazendo a inclusão social de camadas antes excluídas, alterando 
a tradicional lógica meritocrática que pautava a seleção de candidatos à universidade. O desprestígio dos saberes necessários ao ensino tem sido denunciado por muitos estudos, uma vez que a formação dos docentes da educação superior, por intermédio dos mestrados e doutorados, não contempla os saberes da docência. Esse aspecto se reflete, posteriormente, nos valores que o professor atribui ao ato de ensinar e no como ele o faz.

Nos cursos de licenciatura esse impacto é ainda maior, dada a sua natureza conceitual baseada na preparação para a docência, objeto principal desses cursos. Nesse caso, a forma como os docentes ensinam constitui o conteúdo da formação de professores. Ou seja, enquanto ensina, o docente da universidade está ensinando a ensinar. E, dado o vácuo da sua formação, nem sempre essa dimensão é suficientemente compreendida por ele. Torna-se, portanto, salutar questionar como o docente universitário tem pensado o seu papel no interior desses cursos, a partir da experiência em programas institucionais de iniciação à docência.

\section{COM QUEM DIALOGAMOS}

Para pensar no papel dos docentes universitários e relacionar a importância desse papel com a formação inicial de professores, algumas questões necessitam ser pontuadas. Essas questões, em nosso entendimento, podem ser delimitadas pelas compreensões dos saberes e trajetórias pessoais dos docentes, de suas compreensões de currículo, do entendimento de que precisam considerar aspectos da experiência/ prática pedagógica dos docentes universitários e a relação que estes estabelecem com os sistemas de ensino. Dessa forma, optamos por fazer uma breve discussão teórica, trazendo os autores em que nos pautamos a respeito de tais aspectos.

Compreender os saberes e trajetórias de docentes tem consistido campo de investigação na educação há alguns anos e, segundo Zabalza (2004, p. 131), algumas vezes no contexto universitário, "a dimensão pessoal dos professores desaparece ou torna-se invisivel no exercício 
profissional". Assim, há dois aspectos no tocante a essa dimensão pessoal que necessitam ser considerados, quais sejam, a satisfação pessoal e profissional e a carreira docente. Neste estudo focalizamos o segundo aspecto por este considerar, entre outros, os momentos pelos quais os docentes passam até atingirem a plenitude profissional.

Quando se pensa em currículo, é comum compreendermos seus limites num rol de conteúdos. Entretanto, vale a reflexão que expande essa noção inicial, pois o currículo revela valores e opções teóricopráticas que precisam ser discutidas e assumidas intencionalmente. Para Sacristán (1998, p. 122) , "a discussão sobre o que ensinar centrouse na tradição anglo-saxã, em torno do currículo, um conceito definido, primitivamente, nos fins e conteúdos do ensino, que mais tarde se ampliou" e que, muitas vezes, desprezou a análise e as decisões sobre o currículo, pautando-se mais enfaticamente em como organizá-lo e manejá-lo. Em nosso entendimento, a discussão sobre o tema se inicia quando se decide qual currículo privilegiar. Alguns estudos que tratam do currículo de cursos de licenciatura (BORGES, 2012; OLIVEIRA; ROSA, 2008) afirmam que o Pibid permite pensar sobre algumas questões e, nessa direção, possibilita que se reflita sobre o currículo dos cursos de licenciatura e como este influencia as ações empreendidas. Nesse sentido, o currículo pode ser vislumbrado como uma construção social, em que os atores são os responsáveis por sua seleção, condução e execução. (GOODSON, 2001).

Forster (2011, p. 252) cita a relevância de se compreenderem os limites da formação acadêmica e a "importância de esta ser realizada em diálogo com a escola e seus professores, e sempre com o entendimento de que estamos condicionados por um contexto sociopolítico desafiador". De forma que, quando o Pibid se insere no espaço escolar, existe a possibilidade de pensar sobre com qual currículo se quer trabalhar na escola e também por meio de qual currículo estão se formando os futuros professores e, nessa direção, refletir na sua construção social. As práticas curriculares não se apresentam descoladas da formação inicial de professores e da consciência dos docentes universitários em relação ao seu desenvolvimento profissional, uma vez que as lacunas da formação inicial pressupõem que o papel da instituição formadora 
e seus currículos necessitam ser repensados (GATTI, 2011, p. 89). Ainda as articulações do currículo com a formação de professores, para Garcia (2011), possibilitam pensar em outro modelo de professor.

Dessa forma existe uma relação da experiência e da prática pedagógica do docente com a compreensão do conceito de formação. Este conceito, de acordo com Marcelo Garcia (1999), pode ser entendido de diferentes formas, tais como uma função social de transmissão de saberes, um processo de desenvolvimento e de estruturação da pessoa ou, ainda, a formação como instituição, quando esta se responsabiliza pela planificação e pelo desenvolvimento das atividades de formação. Para Cunha (2009, p.169), “a formação não é um constructo arbitrário” e, por isso, é necessário que seja objeto de análise constantemente, para tornar possível combater a ideia de que quem sabe fazer sabe ensinar, expressão que orienta a captação de docentes no ensino superior (CUNHA, 2010). Afinal, no caso das licenciaturas, os docentes estarão realizando a formação de sujeitos que irão atuar nas escolas e terão como ponto de partida determinada concepção de educação e de ensino. Essa relação com as escolas, no caso compreendida como os sistemas de ensino, também apresenta influências sobre essas concepções. Entre outras, duas concepções de formação são as mais recorrentes: a do professor como técnico e a do professor como profissional. A primeira é baseada na racionalidade técnica, em que existe uma separação entre o "mundo acadêmico e o mundo da prática", e se busca "propiciar um sólido conhecimento básico-teórico no início do curso [...] para, ao final, chegar à prática profissional com os estágios usuais de final de curso" (SCHNETZLER, 2000, p. 21). A lógica é a apreensão do conhecimento teórico primeiramente, para posterior aplicação desse conhecimento na prática, quando os futuros professores são encaminhados para as escolas. A segunda, a formação do professor como um profissional, é compreendida numa perspectiva cultural, científica e pedagógica consistente, construída durante a formação universitária inicial.

Entretanto, nem sempre os professores universitários refletem sobre os modelos de formação. Exercem suas práticas de forma intuitiva, correndo o risco de viver incoerências entre seus discursos e suas práticas, não estabelecendo relações entre o currículo e a formação 
inicial de professores. Vaillant e Marcelo Garcia (2001), numa visão crítica, destacam que

[...] a formação inicial de professores ao longo da história tem sido desenvolvida por instituições específicas, por sujeitos especializados e mediante um currículo que estabelece a sequência e o conteúdo instrucional do programa formativo (VAILLANT; MARCELO GARCIA, 2001, p. 37, tradução nossa).

Resgatando a bibliografia que informa sobre os estudos a respeito do Pibid, poucos são os trabalhos que investigam a docência universitária apontando que esta ainda não é vista como prioridade quando se pensa na melhoria da formação inicial de professores. 0 silenciamento em relação à docência universitária e ao desenvolvimento profissional do docente da universidade provavelmente é resultado de anos em que a atuação na universidade vem funcionando na lógica de que quem sabe fazer sabe ensinar. Entretanto, no conceito de docência superior/universitária estão imbricadas, conforme Cunha e Isaia (2003, p. 372), “atividades desenvolvidas pelos professores para a preparação de futuros profissionais, baseadas não somente em conhecimentos, saberes e fazeres, mas também nas relações pessoais e afetivas". Assim, a docência é um amálgama da dimensão técnica com a pessoal. Ou seja, o professor exerce uma tarefa complexa em que estão implicadas as dimensões cognitivas, culturais e subjetivas (CUNHA, 2010). Com isso, debater sobre a formação em docência universitária não se resume à exploração das estruturas acadêmicas necessárias para levar a termo essa formação, mas implica discutir a profissão docente universitária, como lembra Imbernón (2012). Portanto, é preciso questionar: é o docente universitário um profissional do ensino? Ele tem consciência disso? Os docentes universitários têm consciência de que o seu desenvolvimento profissional não ocorre somente pela pesquisa nos cursos de pósgraduação?

O conceito de desenvolvimento profissional "pressupõe uma abordagem na formação de professores que valorize o seu caráter contextual, organizacional e orientado para a mudança” (MARCELO GARCIA, 1999, p. 137). Esse termo é o que se adapta melhor à concepção do docente como profissional do ensino, porque o desenvolvimento 
oferece a ideia de "evolução e continuidade", o que supera a ideia de uma formação e posterior aperfeiçoamento, afirma o autor.

\section{O PERCURSO METODOLÓGICO}

A pesquisa em questão, de cunho qualitativo (BOGDAN; BIKLEN, 1994), foi realizada com nove formadores de professores de Biologia, de Física e de Matemática, coordenadores de subprojetos do Pibid de três universidades (duas públicas e uma comunitária) localizadas no Sul do país. Destacamos que a pesquisa foi submetida ao Comitê de Ética em Pesquisa e por ele aprovada e que, para a preservação da identificação, as universidades e os sujeitos participantes são citados com códigos. Dessa forma, as universidades foram identificadas pelos números 1, 2 e 3, e os participantes tiveram sua identidade preservada com a utilização de um código (B1: Biologia da Universidade 1; F1: Física da Universidade 1; M1: Matemática da Universidade 1, e assim sucessivamente). Destacamos ainda que, nas três universidades, a implementação do Pibid ocorreu a partir da participação no primeiro edital, disponibilizado em 2007 (BRASIL, 2007). Portanto, as atividades do programa se iniciaram nas universidades em 2008.

Primeiramente, analisou-se o perfil acadêmico dos docentes, considerando-se a identificação profissional, a formação acadêmica e a atuação profissional, dados acessivveis por meio de consulta ao Currículo Lattes. Posteriormente, utilizou-se a entrevista semiestruturada (RICHARDSON, 2011). O roteiro de entrevista foi composto por 16 questões distribuídas em quatro blocos, quais sejam: a) saberes e trajetórias pessoais; b) currículo; c) experiência e prática pedagógica, e d) relação com os sistemas de ensino.

As entrevistas tiveram duração média de 50 minutos e foram transcritas. Optamos pela norma culta da linguagem nas transcrições sem, contudo, desconsiderar o sentido original do que o entrevistado queria dizer. As falas geradas pelas entrevistas foram analisadas à luz da análise textual discursiva (ATD) (MORAES; GALIAZZI, 2007, p. 7) que se trata de "uma metodologia de análise de dados e informações de 
natureza qualitativa com a finalidade de produzir novas compreensões sobre os fenômenos e discurso". Essa metodologia se situa entre a análise de conteúdo e a análise do discurso e, ultimamente, tem sido bastante utilizada em pesquisas no ensino de Ciências.

Para a análise das entrevistas, uma primeira leitura das falas, considerada o corpus da análise, permitiu a fragmentação das transcrições. Em seguida, ocorreu o processo de unitarização, em que houve a desmontagem dos textos, focalizando detalhes e componentes que forneceram um novo sentido ao texto, sem perder de vista os objetivos do estudo. Produzimos, então, as unidades de sentido como elementos constituintes da desconstrução dos depoimentos coletados. Na etapa posterior, as unidades de sentido foram submetidas a um processo de categorização emergente que considerou os objetivos do estudo, o referencial teórico da pesquisa e aspectos relevantes presentes no roteiro de entrevista. Por fim, a última etapa possibilitou que se construíssem os metatextos em diálogo com os dados da literatura apresentados inicialmente.

\section{RESULTADOS}

Os resultados e a discussão dos dados foram organizados a partir da análise do perfil dos formadores de professores e da análise das entrevistas. Em relação a esta segunda, os dados foram discutidos com base em dois aspectos primordiais presentes em todas as entrevistas, a saber, como a experiência no Pibid impacta o (re)pensar no formato dos currículos dos cursos de licenciatura e sobre a própria formação e desenvolvimento profissional dos formadores.

\subsection{Conhecendo o perfil dos formadores de professores}

Foram analisados os Currículos Lattes dos nove docentes que participaram da pesquisa no que diz respeito à identificação profissional, à formação acadêmica e à atuação profissional. Nesse exercício foram observados os seguintes aspectos: a) cursos de atuação; b) formação acadêmica profissional e c) atuação profissional. 
Em relação ao primeiro item, houve a intenção de verificar há quanto tempo o professor ministra aulas em curso de licenciatura. No segundo, buscamos avaliar a sua formação na graduação e na pósgraduação e a influência dessa condição na sua atuação como formador de professores. Por fim, observamos a sua atuação profissional, bem como quais disciplinas ministrou, há quanto tempo atua no ensino superior, se coordena projetos e, se sim, de qual natureza, e se participa ou participou de instâncias administrativas da universidade. Os formadores de professores envolvidos nesta pesquisa estão na coordenação dos subprojetos do Pibid nas respectivas áreas em um intervalo de um a quatro anos.

Em relação à Biologia, dos três sujeitos entrevistados, pudemos inferir que somente B1 não ministra disciplinas integradoras ${ }^{2}$ da Biologia. Em relação à atuação no ensino superior, B1 e B2 atuam há mais de 20 anos nesse nível de ensino; e todos três já participaram de projetos de extensão e de instâncias administrativas da universidade. Em relação à Física, os docentes F2 e F3 atuam na formação pedagógica da área na condição de docentes da universidade. O professor F1 detém pequena experiência (três anos) no ensino superior e não ministra disciplinas integradoras de Física. Como no caso anterior, os três docentes apresentam envolvimento com a administração acadêmica. Na Matemática, os professores M1 e M2 possuem menos experiência no ensino superior; ministram disciplinas integradoras da Matemática e atuam em projetos de extensão. O professor M3 tem envolvimento com a administração da universidade. Quando analisamos os docentes por universidade, todos os da Universidade 2 ministram disciplinas integradoras, enquanto os das Universidades 1 e 3, não. Em nosso entendimento, mais importante do que atuar na formação pedagógica dos futuros professores é a consciência dos formadores de professores em relação à especificidade do profissional a ser formado no curso em que atuam.

Assim, reconhecer a trajetória de formação e de atuação dos formadores de professores nos pareceu importante para este estudo e vem ao encontro do que preconiza Garcia (2011) quando menciona a formação de outro modelo de professor: Neste texto são
consideradas disciplinas
integradoras as que
trabalham o conteúdo
específico à luz do ensino
de Biologia, de Física e de
Matemática, e disciplinas
específicas as que
trabalham os conteúdos
específicos dos campos
anteriormente citados
(GONÇALVES; MARQUES,
2016). 
Privilegiando e excluindo saberes do processo de profissionalização, distribuindo-os em séries temporais ao longo da duração do curso do aluno, estabelecendo competências, atribuições e responsabilidades nos processos de formação, instituindo distinções e visões acerca do ensino e da aprendizagem, o currículo consagra uma política de espacialização do conhecimento e institui relações de poder-saber que capacitam os sujeitos diferentemente para a ação e a participação no mundo (p. 288).

Entendemos que a participação do docente que ministra tanto as disciplinas integradoras quanto as específicas na licenciatura possibilita (re)pensar o currículo do curso, mesmo que, por vezes, este aspecto não seja consciente para os docentes, o que poderia qualificar o processo formativo dos futuros professores. A atuação em cursos de licenciatura (independentemente se em disciplinas integradoras ou não) é uma das condições presentes no documento que regulamenta o Pibid, a Portaria nº 096/2013, em seu Anexo I, cap. VI, seção III, art. 34, item V (BRASIL, 2013). Nesse caso, a legislação supõe que os docentes estejam envolvidos com o currículo e comprometidos com a sua execução.

\subsection{Como a experiência no Pibid permite (re)pensar o curso de formação inicial de professores}

Observa-se que o programa tem propiciado algumas críticas e, consequentemente, reflexões acerca do processo formativo no interior da estrutura curricular dos cursos de formação inicial. Dizem os docentes:

\footnotetext{
"Eu acho que o currículo não está adequado ao ensino de Física. Não sei em outras licenciaturas, mas, quanto à Física, o problema é que o aluno não vê um foco principal nem na licenciatura, nem no bacharelado". (F1) "O nosso curso de licenciatura tem tudo o que o bacharelado tem e mais toda a parte que chamamos de pedagógica. Essa parte pedagógica entra no currículo desde o primeiro semestre, por isso digo que o curso de licenciatura é muito carregado". (B1)
}

Observamos, pelos depoimentos, que os docentes reconhecem os currículos em relação ao profissional a ser formado e revelam a importância das discussões a esse respeito. No entanto, apesar de 
reconhecerem as distinções entre os objetivos do bacharelado e os da licenciatura, as falas apontam a falta de clareza do projeto pedagógico do curso em relação aos profissionais que se pretende formar. Por outro lado, há o entendimento de que houve melhorias nos cursos de licenciatura a partir das Resoluções CNE/CP n 1 e n² 2/2002 (BRASIL, 2002a, 2002b)³, que provocaram a discussão do formato e do conteúdo desses cursos. Há indícios dos resultados dessas normativas que podem ser observados nas manifestações de nossos interlocutores:

[...] ainda não temos um número de horas suficiente para uma formação mais apurada, mas também não sei como dar conta disso diante dessa limitação de tempo para atender as questões dos conhecimentos específicos da Biologia e das questões metodológicas e práticas da licenciatura. Nós tivemos alguns avanços. Antes, os alunos iam para o estágio no final, no último semestre; agora, não, eles passam quatro semestres dentro da escola. Então, acho que houve avanços [...]. (B2)

[...] eu ainda acho que há espaço para melhorar. Começamos um processo de reformulação quando foram separados os projetos pedagógicos das duas terminalidades e realmente criados dois quadros de sequência curricular: um próprio da licenciatura e um próprio do bacharelado, com disciplinas mais específicas que faziam falta [...]. (F3)

[...] quando se pensou o novo currículo, objetivava-se conseguir atender parte da formação e, ao mesmo tempo, priorizar a questão do conteúdo [...]. (M3)

Percebe-se que, apesar dos avanços registrados pelos professores, ainda há uma lógica que separa o conhecimento sobre o conteúdo da matéria de ensino do conhecimento pedagógico. É reconhecido que a influência da legislação e a alteração ocorrida nos estágios fizeram com que tal questão fosse ressaltada, o que possibilitou mais discussões a respeito. Nesse sentido, Forster faz um alerta:

A formação para o ensino ainda está organizada em torno de lógicas disciplinares, fragmentadas, nas quais as disciplinas não têm relação entre si e possuem pouco impacto sobre os alunos. Essa formação também é concebida segundo um modelo aplicacionista do conhecimento, no qual a "teoria” antecede a "prática”. (FORSTER, 2011, p. 244).

Entretanto, parece que o Pibid tem contribuído para que se repense essa lógica, consequentemente, o programa formativo, que

${ }^{3}$ No período de realização da pesquisa, estas resoluções estavam em vigência. 
inclui o currículo dos cursos de licenciatura. Essa discussão auxilia a que se repense a lógica no ensino superior em que, muitas vezes, o processo de ensino e aprendizagem ocorre dentro do modelo recepçãotransmissão e há falta de diálogo entre as próprias disciplinas do curso e entre estas e a escola. E como isso vem acontecendo? Provavelmente porque, na medida em que há uma aproximação inicial dos licenciandos com "o chão da escola”, o programa também permite a aproximação do docente universitário com esse espaço, favorecendo a possibilidade de olhar para o currículo numa outra perspectiva, acreditando que "a escola como espaço formativo tem muito a ensinar à universidade" (FORSTER, 2011, p. 246). Nesse caso o docente reconhece a necessidade de conhecer a realidade escolar e que a parceria com a escola o possibilita (re)pensar a sua prática docente, principalmente na formação dos futuros professores. Dizem eles:

Só quem estudou para isso, quem sabe as dificuldades, os problemas, tem de conhecer a realidade dali, daquela escola particular, estadual, ou municipal. Você tem de reconhecer a realidade dos alunos. E nós não sabemos aqui, no curso. Também muitos dos nossos alunos desconhecem essa realidade. Então, tem de mudar o currículo, conciliando o Pibid com a escola. (F1)

[...] faltam, entretanto, disciplinas integradoras que abordem o que o Pibid proporciona para os estudantes e que o curso não proporciona [...]. (F3)

No entanto, também se evidencia a discussão do currículo no Pibid e para o Pibid, ou seja, são discussões que ocorrem no interior de um programa que existe relacionado aos cursos de licenciatura, mas que ao mesmo tempo estão distantes dos docentes que formam professores e que não participam do Pibid. A fala de um docente explicita esse aspecto:

A articulação do currículo existe somente dentro do próprio Pibid. [...] os alunos têm disciplinas da área "dura”, mas eles não sabem depois o que fazer com os conteúdos que aprendem lá. Não são disciplinas que eles conseguem articular para a área de ensino, para dar uma formação na escola. [...] Então, o que o Pibid está fazendo? Bom, eles estão tendo de produzir oficinas; eles estão tendo de estudar conceitos que o próprio curso deveria explorar, conceitos que estão na área de estudo deles, para poder articulá-los com as metodologias e trabalhar em sala de aula. (M1) 
O fragmento anterior expõe a fragilidade do que os licenciandos vivenciam nas disciplinas específicas em que se privilegia a compreensão do conteúdo sem que o licenciando, futuro professor, consiga realizar a mediação didática. Para que esta ocorresse precisaria haver a integração do conhecimento acadêmico específico ao conhecimento pedagógico sobre o processo de ensino e aprendizagem (SCHNETZLER, 2000).

Outra questão levantada é a de que mesmo com as restrições apontadas, parece importante destacar que o Pibid está proporcionando aos docentes e licenciandos um contato maior com a pesquisa sobre 0 ensino. A respeito desse aspecto destacamos as falas a seguir.

[...] a questão da pesquisa no ensino é importante para a formação do professor, ele se dá conta de que receber o diploma e ir para sala de aula não significa que ele deixou de ser uma pessoa que pode pesquisar o ensino, pode pesquisar em cima da sua própria prática [...]. (F3)

[...] vamos incluir no curso de licenciatura um pouco mais a parte da pesquisa em educação e algumas modificações para favorecer a entrada do aluno na escola. Já passamos muita coisa para o primeiro ano; para eles começarem a vivenciar essa experiência desde o início [...]. (B3)

Esse aspecto referente à pesquisa no ensino poderá ser reforçado, no currículo do curso, quando, a partir dos próprios docentes, se começar a ter sugestões de disciplinas que tratem da dimensão do ensino relacionado a uma prática de pesquisa.

\subsection{Como a participação no Pibid influenciou a docência universitária dos formadores de professores}

Percebemos que todos os sujeitos entrevistados citam o fato de que o programa propiciou o repensar também de seus processos de ensinar e aprender no ensino superior. Essa condição, de certa forma, vem favorecendo os formadores de professores a repensarem suas práticas docentes e a buscarem, por meio do estudo e da pesquisa, elementos que permitam responder a essas lacunas.

[...] eu pensava ter chegado a um consenso de como avaliar, como ensinar, e hoje eu vivo uma confusão. O que ensinar? Eu ainda não tenho o conceito 
fechado do que é ensinar. No ensino médio eu tenho uma ideia do que é ensinar Física, eu consegui pensar um pouco. Mas, na universidade e na formação de professores, eu ainda não sei. (F1)

[...] então, eu tenho de pesquisar, eu tenho de buscar, e isso tem sido muito gratificante para mim [...]. (M2)

De certa forma, esse aspecto faz com que o docente repense sua atuação na universidade e pense em seu próprio desenvolvimento profissional como docente. O programa passa, assim, a ser um estímulo, pois, para aprender, é necessário estar motivado, conhecendo o interesse e as contribuições que essa aprendizagem trará (ZABALZA, 2004).

Além desse aspecto, foi apontada, por um docente, a importância do Pibid na reformulação das políticas de formação de professores.

[...] eu não consigo pensar numa política de formação de professores que seja esfacelada dentro da universidade. Por exemplo, pensar em formação de professores e pensar em licenciaturas não é nem questão de ter um centro de formação de professores próprio; mas é pensar em uma política da formação de professores dentro da universidade, diretamente ligado ao Pibid. Pensar nessa estrutura ou nessa forma que a gente criou, que construiu para trabalhar [...]. (F3)

Outro aspecto evidenciado é o da contribuição da aproximação com a escola para o desenvolvimento profissional docente. Como afirma B1,

[...] os alunos e professores na escola me ensinam muito, porque o meu contato era só com a academia. Eu não tinha vivência de escola. [...] Eu não coordeno da universidade, eu coordeno da escola. Isso me ajuda bastante na minha prática e também em como eu procedo com os meus alunos. (B1)

Essa posição é ratificada por outros docentes:

[...] eu estou tendo de ler muito, estou tendo de estudar além do que eu estava estudando para dar conta de tudo isso que estamos fazendo. (M1) [...] aproximei-me, pois estava um pouco distante da escola; atualizeime no sentido de ver a realidade das escolas, embora eu sempre tivesse estagiários [...]. (F2) 
A aproximação com a escola é primordial quando se pensa que esses docentes atuam em cursos de licenciatura e que, muitas vezes, há uma crítica do uso da escola como espaço somente de prática. Isso remete à discussão da dicotomia teoria-prática, debatida faz anos nos cursos de formação e que vem sendo superada há uns 10 anos.

Na mesma direção, M2 reconheceu que sentia falta “desse contato direto com o professor, e o programa me aproximou muito da escola de meus orientandos, que são todos professores [...]” (M2).

Vale ressaltar também essa importância para quem exerce a coordenação de cursos, caso de B3, que assim se manifestou:

[...] para mim tem sido fundamental não só na condição de professora, bem como também na de coordenadora do curso, porque, na correria, na rotina do dia a dia, muitas vezes não conseguimos ir até uma escola, vivenciar a realidade de uma escola, ficamos muito presos na universidade. O Pibid abriu muito essas portas que até então estavam um pouco fechadas, porque agora eu consigo estar na escola, eu consigo vivenciar o que ocorre na escola; eu consigo conversar com as professoras, saber das mudanças [...]. (B3)

Refletindo sobre os depoimentos, compreendemos que "o desenvolvimento profissional docente implica interação com os contextos espacial e temporal" em que o primeiro considera o ambiente social, organizativo e cultural no qual se realiza o trabalho docente; e o segundo se refere à dimensão biográfica ou ao momento que se está vivendo como influente na atitude docente (VAILLANT; MARCELO GARCIA, 2012, p. 169). Assim, pode-se inferir que o programa possibilitou repensar o contexto espacial e auxiliou na reflexão dos docentes dessas instituições em relação à sua prática docente. O contexto espacial assumiu uma condição relevante, porque se vai ao espaço escolar e se extrapola o usual espaço da universidade.

O Pibid parece estar proporcionando o que os autores há pouco citados denominam de modelo de ressonância colaborativa ${ }^{4}$, em que entre a instituição formadora e a coformadora (a escola) existe uma visão mais complexa, com maior potencial de desenvolvimento. Nesse

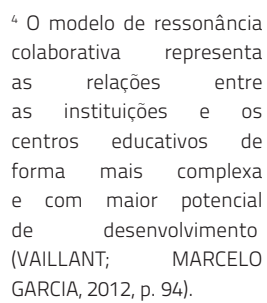

${ }^{4} \mathrm{O}$ modelo de ressonância colaborativa representa as relações entre as instituições e os centros educativos de forma mais complexa e com maior potencial de desenvolvimento (VAILLANT; MARCELO GARCIA, 2012, p. 94). 
processo, vale destacar que os processos de ensinar e aprender, na formação de professores, ocorrem como um fluxo de experiências, contextos e situações diferenciados, revelando que há a formação tanto do licenciando, como do docente ao longo do processo. Mesmo que muitas vezes esta última não seja consciente.

Poucos formadores de professores deixaram de reconhecer as contribuições da experiência sobre a própria prática, mesmo que essa se reflita na satisfação com a formação dos licenciandos. De forma que parece que essa convivência constitui o que alguns autores chamam de comunidade aprendente (GALIAZZI; MORAES, 2013, p. 260), em que

[...] os participantes aprendem coletivamente a ser professores ao desenvolverem atividades que tenham um objetivo comum, imersos na linguagem. Aprendem ao falar, ao escrever, ao ensinar, no movimento dos discursos científicos, pela pesquisa, a partir dos contextos de vivência em direção à produção de argumentos próprios do coletivo sobre os temas de estudo. (GALIAZZI; MORAES, 2013, p. 260).

Nessa comunidade estabelecem-se os objetivos comuns e os aspectos individuais que são partilhados e (re)elaborados considerando os sujeitos envolvidos. Assim, revela-se a condição formativa do programa, envolvendo muitas questões que contribuem para a melhoria desses cursos de licenciatura, em particular. Além disso, sendo o Pibid de abrangência nacional, o programa possibilita pensar na constituição de redes de aprendizagem e no que interessa melhorar a qualidade do ensino e da aprendizagem, o que pode contribuir para o desenvolvimento profissional de todos os atores envolvidos.

\section{CONSIDERACÕES FINAIS}

Desde a sua implementação nas universidades brasileiras, o Pibid tem possibilitado a ampliação das discussões relacionadas com diversos aspectos da formação inicial e continuada de professores, bem como tem contribuído para a reflexão da docência universitária no contexto atual. Essa pode ser a chave para se refletir sobre a docência universitária considerando o seu reconhecimento pelos docentes do ensino superior 
e sobre o professor que se pretende formar para a educação básica, em que pese ser este um sujeito qualificado para enfrentar os desafios que se apresentam no século XXI.

O Pibid, como política de formação, também vem se constituindo um potente dispositivo de aproximação da universidade com as escolas e com o sistema educativo como um todo. Nesse sentido, o programa vem permitindo que se vivenciem situações que proporcionem a reflexão dos processos formativos empreendidos e produzidos, bem como os saberes reconhecidos pelos docentes universitários. No entanto, a relação desses processos com o desenvolvimento profissional dos docentes ainda não é suficientemente explicitada, e esse foi um dos objetivos desta investigação. Foi, porém, possível compreender que os docentes expressam que aprendem especialmente sobre: a realidade concreta da escola pública; os saberes que os professores da educação básica mobilizam em suas situações de práticas; os processos vivenciados pelos licenciandos ao conviverem com o ambiente escolar; a valorização da pesquisa sobre a própria prática; a inclusão dos saberes da pesquisa no currículo das licenciaturas; a valorização de comunidades aprendentes na parceria universidade-escola; a articulação dos saberes profissionais que constituem os currículos das licenciaturas no contexto acadêmico.

O enfrentamento da realidade coloca em xeque o currículo das licenciaturas e exige um significativo esforço de síntese da relação entre os saberes profissionais docentes de cada área disciplinar do currículo. Desestabiliza a ordem com que eles se apresentam na academia e convoca os professores a ensinar e aprender com seus alunos e colegas professores, no contexto da escola. E essa pode ser uma condição de relevo pedagógico, uma especial contribuição que vem sendo dada pelo Pibid. Especificamente em relação à investigação empreendida muitos formadores expressaram estar pensando pela primeira vez em quais contribuições o Pibid teve em seu desenvolvimento profissional a partir da entrevista. Na verdade tal aspecto não é consciente para esses sujeitos no desenvolvimento da profissão e, nesse sentido, somente por possibilitar essa reflexão a pesquisa empreendida já apresenta alguns ganhos. 
Mesmo considerando que, como qualquer programa, o Pibid tem seus limites, cremos que seu sucesso estará na dependência do compromisso daqueles que o desenvolvem. Como programa, requer investimento e crença no trabalho coletivo. Dessa forma, futuras pesquisas, mais em longo prazo, com docentes universitários que dele participaram/participam poderão trazer compreensões acerca de contribuições aos cursos de formação inicial de professores.

\section{Agradecimentos}

À Fundação de Amparo à Pesquisa do Estado da Bahia (FAPESB) pela concessão da bolsa e aos docentes que participaram da pesquisa.

\section{Referências}

AMBROSETTI, N. B.; TEIXEIRA, M. B.; RIBEIRO, M. T. M. A experiência do Pibid na perspectiva dos formadores das licenciaturas. In: ENDIPE, 16. 2012, Campinas. Anais... Campinas, 2012.

ARAÚJO, M. L. F. Pibid Biologia na UFRPE: dois anos de unidade teoriaprática na parceria universidade-escola. In: ENDIPE, 16., 2012, Campinas. Anais... Campinas, 2012.

BOGDAN, R. C.; BIKLEN, S. K. Investigação Qualitativa em Educação. Trad. M. J. Alvarez, S. B. Santos e T. M. Baptista. Rev. A. B. Vasco. Portugal: Porto Editora, 1994.

BORGES, L. F. F. Um currículo para formação de professores. In: VEIGA, I. P. A.; SILVA, E. F. (Orgs.). A escola mudou. Que mude a formação de professores! 3. ed. Campinas, SP: Papirus, 2012. p. 35-60.

BRASIL. Coordenação de Aperfeiçoamento de Pessoal de Nivel Superior. Portaria $n^{\circ}$ 096, de 18 de julho de 2013. Fica aprovado, na forma dos Anexos I e II, o Regulamento do Programa Institucional de Bolsa de Iniciação à Docência (Pibid). Brasília, 2013. Disponível em: < http:/ / www. 
capes.gov.br/educacao-basica/capespibid/documentos-pibid>. Acesso em: 31 out. 2013.

- Ministério da Educação. Portaria Normativa n 16, de 23 de dezembro de 2009. Dispõe sobre o PIBID - Programa Institucional de Bolsa de Iniciação à Docência. Diário Oficial [da] República Federativa do Brasil, Poder Executivo, Brasília, 24 dez. 2009. Seção 1, p. 91. Disponível em: <http://www.capes.gov.br/images/stories/download/bolsas/ Portaria16_241209.pdf>. Acesso em: 30 jan. 2012.

- Ministério da Educação. Portaria Normativa n³8, de 12 de dezembro de 2007. Dispõe sobre o Programa Institucional de Bolsa de Iniciação à Docência - PIBID. Diário Oficial [da] República Federativa do Brasil, Poder Executivo, Brasília, DF, 13 dez. 2007. Seção 1, p. 39. Disponível em: <http://www.capes.gov.br/images/stories/download/ diversos/Portaria72_Pibid.pdf>. Acesso em: 30 jan. 2012.

Resolução do Conselho Nacional de Educação/Conselho Pleno n² 1, de 18 de fevereiro de 2002. Institui Diretrizes Curriculares Nacionais para a Formação de Professores da Educação Básica, em nível superior, curso de licenciatura, de graduação plena. Diário Oficial [da] República Federativa do Brasil, Poder Executivo, Brasília, DF, 9 de abril de 2002a. Seção 1, p. 31. Disponível em: <http://portal.mec.gov.br/cne/arquivos/ pdf/rcp01_02.pdf>. Acesso em: 30 jan. 2012.

Resolução do Conselho Nacional de Educação/Conselho Pleno $n^{\circ} 2$, de 19 de fevereiro de 2002. Institui a duração e a carga horária dos cursos de licenciatura, de graduação plena, de formação de professores da Educação Básica em nível superior. Diário Oficial [da] República Federativa do Brasil, Poder Executivo, Brasília, DF, 4 de março de 2002b. Seção 1, p. 9. Disponível em: <http://portal.mec.gov.br/cne/arquivos/ pdf/CP022002.pdf>. Acesso em: 30 jan. 2012.

CARDOSO, M.; ReNDA, V. L. B. de S.; CUNHA, V. M. P. Percepções do licenciando quanto à sua formação: uma experiência no PIBID. In: ENDIPE, 16., 2012, Campinas. Anais... Campinas, 2012. 
CARVALHO, A. P.; RAZUCK, R. C. S. R. O Programa Institucional de Bolsa de iniciação à docência sob a ótica de Professores Supervisores de Química: contribuições ao processo de formação docente. Revista Iberoamericana de Educación, Madri, v. 68, n. 1, p. 9-28, 2015.

CUNHA, M. I. (Org.). Trajetórias e lugares de formação da docência universitária: da perspectiva individual ao espaço institucional. Araraquara, SP: Junqueira \& Marin Editores/CAPES/CNPq, 2010.

. Inovações pedagógicas na Universidade. In:CUNHA, M. I.; SOARES, S. R.; RIBEIRO, M. L. (Orgs.). Docência universitária: profissionalização e práticas educativas. Feira de Santana: UEFS Editora, 2009. p.169-189.

CUNHA, M. I.; ISAIA, S. M. A. Formação do docente de Instituições de Ensino Superior. In: MOROSINI, M. C.; GRILLO, M. C.; FRANCO, M. E. Dal P.; CUNHA, M. I.; ISAIA, S. M. A. (Orgs.). Enciclopédia de Pedagogia Universitária. Porto Alegre: FAPERGS/RIES, 2003. p. 368-375.

CUNHA, M. I.; SOARES, S. R.; RIBEIRO, M. L. (Orgs.). Docência universitária: profissionalização e práticas educativas. Feira de Santana: UEFS Editora, 2009. p.169-189.

FELIICIO, H. M. S. Os desafios e as conquistas na formação de professores vivenciados pela coordenação de área no PIBID/UNIFAL - MG. In: ENDIPE, 16., 2012, Campinas. Anais... Campinas, 2012.

FELÍCIO, H. M. S.; GOMES, C.; ALLAIN, L. R. O PIBID na ótica dos licenciandos: possibilidades e limites no desenvolvimento do programa. Educação, Santa Maria, v. 39, n. 2, p. 339-352, maio/ago. 2014.

FORSTER, M. M. S. Universidade/escola: diálogos e reflexões em parceria. In: ZANCHET, B. M. B. A.; PINTO, M. G. C. S. M. G.; FORSTER, M. M. S.; FAGUNDES, M. C. V. (Orgs.). Processos e práticas na formação de professores: caminhos possiveis. Brasília: Liber Livro Editora, 2011. p. 239-256.

GALIAZZI, M. C.; MORAES, R. Comunidades aprendentes de professores: uma proposta de formação no Pibid-Furg. In: GALIAZZI, M. C.; COLARES, 
I. G. (Orgs.). Comunidades aprendentes de professores: o Pibid na Furg. ljuí: Ed. Unijuí, 2013. p. 259-275.

GARCIA, M. M. A. A reforma em currículos de Licenciatura da UFPEL: impactos nos saberes da formação inicial de professores. In: ZANCHET, B. M. B. A. et al. (Org.). Processos e práticas na formação de professores: caminhos possíveis. Brasília: Liber Livro Editora, 2011. p. 285-299.

GATTI, B. A. (Org.). Políticas docentes no Brasil: um estado da arte. Brasília: UNESCO, 2011. 300p.

GATTI, B. A. et al. Um estudo avaliativo do Programa Institucional de Bolsa de Iniciação à Docência (PIBID). São Paulo: FCC/SEP, 2014. 120p.

GONÇALVES, F. P.; MARQUES, C. A. A Experimentação na Docência de Formadores. Química Nova na Escola, São Paulo, v. 38, n. 1, p. 84-98, fev. 2016.

GOODSON, I. F. O currículo em mudança - Estudos na construção social do currículo. Trad. Jorge Ávila de Lima. Portugal: Porto, 2001. p. 173-194. (Coleção Currículo, Políticas e Práticas).

IMBERNÓN, F. Inovar o ensino e a aprendizagem na universidade. Tradução de Silvana Cobucci Leite. São Paulo: Cortez, 2012.

LEITE, F. G. M. O Programa Institucional de Bolsa de Iniciação à Docência: impactos na didática e na formação docente. In: ENDIPE, 16., 2012, Campinas. Anais... Campinas, 2012.

MARCELO GARCÍA, C. Formação de professores: para uma mudança educativa. Portugal: Porto Editora, 1999. (Coleção Ciências da Educação Século XXI).

MASSENA, E. P. Avaliando a produção científica em torno do PIBID: tendências, relevâncias e silenciamentos. In: ENPEC, 9., 2013, Águas de Lindoia. Anais... Águas de Lindoia, 2013. 
MORAES, R.; GALIAZZI, M. do C. Análise textual discursiva. Rio Grande do Sul: Unijuí, 2007.

OLIVEIRA, A. C. G.; ROSA, M. I. P. Currículo e formação profissional: Cenas do cotidiano de um instituto de pesquisa. Química Nova na Escola, n. 30, p. 49-54, nov. 2008.

RICHARDSON, R. J. Pesquisa social: métodos e técnicas. 3. ed. São Paulo: Atlas, 2011. 334p.

SACRISTÁN, J. Gimeno. O currículo: os conteúdos de ensino ou uma análise prática? In: SACRISTÁN, J. Gimeno; PÉREZ-GÓMEZ, A. I. Compreender e transformar o ensino. Trad. Ernani F. da F. Rosa. 4. ed. Porto Alegre: ArtMed, 1998. p. 120-148.

SCHNETZLER, R. P. O professor de Ciências: problemas e tendências de sua formação. In: SCHNETZLER, R. P.; ARAGÃO, R. M. R. Ensino de Ciências: fundamentos e abordagens. Campinas, SP: UNIMEP, 2000. p. $12-41$.

SOARES, S. R.; CUNHA, M. I. Formação do professor: a docência universitária em busca de legitimidade. Salvador: EDUFBA, 2010. 134p.

VAILLANT, D.; MARCELO GARCíA, C. Ensinando a ensinar: as quatro etapas de uma aprendizagem. Curitiba: Ed. UTFPR, 2012. 242p.

. Las tareas del formador. Ediciones Aljibe: Málaga-España, 2001.

ZABALZA, M. A. O ensino universitário: seu cenário e seus protagonistas. Tradução de Ernani Rosa. Porto Alegre: Artmed, 2004. 239p.

Recebido em 06/02/2016 Aprovado em 18/05/2016 